\title{
Size-dependent nitrogen uptake in micro- and macroalgae
}

\author{
Mette Hein, Morten Foldager Pedersen, Kaj Sand-Jensen \\ Freshwater Biological Laboratory, University of Copenhagen, Helsingørsgade 51, DK-3400 Hillerød, Denmark
}

\begin{abstract}
The role of algal size as a controlling factor for nitrogen uptake kinetics is examined by comparing published values of $\mathrm{N}$ uptake rate and half-saturation constants in micro- and macroalgae. The uptake kinetics differ substantially among algae very different in size. Microalgae take up nitrogen much faster per unit of biomass than macroalgae at both high and low substrate concentrations, and microalgae have significantly higher affinity for nitrogen than macroalgae. These typical differences in the uptake kinetics among small and large algae are commonly attributed to size-specific differences in the relative surface area (SA:V). Regression analysis demonstrates that size-specific variations in the kinetic parameters can be attributed to changes in relative surface area over an extensive range of algal sizes, covering both micro- and macroalgae. These results agree with previously described relationships between maximum uptake rate of nutrients (nitrogen and phosphorus) and SA:V within narrow size-ranges (either phytoplankton or macroalgae), and emphasize the existence of a general coupling between physiological and morphological properties in algae.
\end{abstract}

KEY WORDS: Nitrogen uptake Microalgae - Macroalgae - Allometry

\section{INTRODUCTION}

Size is a fundamental factor in the ecology of algae because their biochemical composition, metabolism, growth and loss processes are all strongly sizedependent (Banse 1976, Shuter 1978, Runge \& Ohman 1982, Smith \& Kalff 1982, Reynolds 1984, Harris 1986. Watson \& McCauley 1988, Agusti 1991, Agusti et al. 1994). Small algae achieve higher rates of photosynthesis, have higher specific growth rates and also a faster transport of nutrients per unit of biomass. Nitrogen is a key element for algal metabolism because it is a main component of algal proteins and enzyme catalyst capacity, and often limits plant growth and biomass (e.g. Lapointe 1987, Hecky \& Kilham 1988, Fong et al. 1993). Hence, the capability to harvest nutrients from the external environment at both high and low concentrations is an important property of the nutritional ecology of algae. Previous studies have shown that the uptake rate of nutrients is correlated with algal size within relatively narrow ranges; e.g. nitrogen and phosphorus uptake by a few macroalgae (Odum et al. 1958, Rosenberg \& Ramus 1984) and phosphorus uptake in several microalgae (Smith \& Kalff 1982). However, the generality of size-dependent nutritional properties in broad-scale comparative studies of algae has not been attempted as yet.

Most of the studies cited above focus on size-dependent functional properties in unicellular algae which span a $10^{8}$-fold weight range (Banse 1976). The inclusion of multicellular macroalgae in the analysis will enlarge the size-span substantially and, thus, enhance the universality of the allometric relationships sought. However, broad quantitative tests of the functional implications of algal size, including both micro- and macroalgae, are surprisingly few, considering their wide application to explain the biological structure and material flow in aquatic ecosystems.

The shortage of broad-scale comparative studies of algal size and physiological properties may be explained by the lack of scaling parameters sufficiently useful for both micro- and macroalgae. The size of microalgae can be determined by either volume, weight or diameter to allow for numerical scaling (e.g. Banse 1976, Shuter 1978, Smith \& Kalff 1982), but this approach is not suitable for macroalgae which do 
not achieve a definite size. However, scaling of algal metabolism to size is often attributed to changes in relative surface area (SA:V), which influences the exchange of gases and solutes across the plant surface due to its effect on transport distances (e.g. Odum et al. 1958, Rosenberg \& Ramus 1984). Furthermore, the SA:V relationship may exert an effect even when the solute concentration is so high that transport to and from the membrane is not limiting, because the flux across the membrane may still be limited by the density of transporters in the plasmalemma and their specific reaction rate (Raven 1984). As the relative surface area also reflects algal thickness, SA:V can be applied as an alternative scaling parameter for sizedependent functional properties. The relative surface area is fairly constant within species compared to the variation encountered among species (Smith \& Kalff 1982, Rosenberg \& Ramus 1984, Hanisak et al. 1988) and, thus, SA:V provides a useful scaling parameter for micro-as well as macroalgae.

The main objective of the present study was, therefore, to test whether the parameters describing nitrogen uptake kinetics differed among algae of different size-classes (micro-versus macroalgae) and, further, to test whether variations in these parameters could be attributed to variations in SA:V, including both microand macroalgae in the analysis.

\section{METHODS}

Suitable nutrient kinetic parameters. We used the Michaelis-Menten constants $V_{\max }$ (the maximum uptake rate) and $K_{\mathrm{m}}$ (the half-saturation constant for nutrient uptake) and the derived constant $\alpha\left(\alpha=V_{\max } / K_{\mathrm{m}}\right)$ to characterize nitrogen uptake kinetics, because Michaelis-Menten kinetics represent the simplest hyperbolic form to describe the uptake rate as a function of substrate concentration. Several methodological problems are, however, associated with the determination of $V_{\max }$ and $K_{\mathrm{m}}$. Nutrient uptake rates are not linear with time (Goldman \& Glibert 1982, Harrison et al. 1989) and are probably controlled by negative feedback as nitrogen pools within the cell are filled (Wheeler 1983, Fujita 1985, Fujita et al. 1988). Surge uptake ( $V_{S}$, sensu Conway et al. 1976) represents the initial filling of internal pools with inorganic nitrogen. This variable is difficult to measure because of its short duration (seconds to minutes in microalgae) and is, therefore, often missed in nutrient uptake experiments. The maximum rate of assimilation of inorganic nitrogen into organic compounds ( $V_{1}$, sensu Conway et al. 1976) is the value usually presented as $V_{\max }$ in the literature. $V_{\mathrm{S}}$ is often considerably higher than $V_{\mathrm{I}}$ and the 2 cannot be separated accurately in most cited ex- periments which will give rise to variability in the $V_{\max }{ }^{-}$ values reported.

$K_{\mathrm{m}}$ is a measure of affinity for nutrient uptake, but represents a mathematical abstraction and its suitability as a measure of nutrient affinity is, therefore, open to question (Healey 1980). The initial slope of the $V$ vs $S$ curve $(\alpha)$ constitutes the third kinetic parameter used in this study. $\alpha$ quantifies the efficiency of nutrient uptake at low substrate concentrations (Healey 1980). Unfortunately, $\alpha$ is only rarely measured or reported in uptake studies. Most $\alpha$-values were, therefore, estimated from $V_{\max }$ and $K_{\mathrm{m}}$.

Data background. We searched the literature for kinetic parameters $\left(V_{\max }, K_{\mathrm{m}}\right.$ and $\left.\alpha\right)$ in micro- and macroalgae. To characterize organism size we used corresponding measurements of $\mathrm{SA}: \mathrm{V}$, when available, or values determined for the particular species in other publications. The final data set consisted of 76 algal species and a total of 840 values for $V_{\max }, K_{m}, \alpha$ and SA:V. Several data sets had to be discarded because of obvious errors in units of uptake rates and conversion of size measurements to SA:V. The entire data set is tabulated and available from the authors on request.

Uptake rates of macroalgae are usually reported as transport rates (sensu Turpin 1988), i.e. scaled to dry weight ( $g \mathrm{~N} \mathrm{~g}^{-1}$ plant DW $\mathrm{h}^{-1}$ ), while microalgal uptake rates are usually scaled to nitrogen content ( $g \mathrm{~N}$ $\mathrm{g}^{-1}$ cell $\mathrm{N} \mathrm{h}^{-1}$ ). Scaling to dry weight was chosen to achieve uniformity in the data set, and uptake rates scaled to nitrogen content were recalculated to transport rates from corresponding information on cell nitrogen content and cell dry weight. When cell dry weight was not available it was estimated from available cell volume data according to the equation in Reynolds (1984, p. 32). Median values were used when several data sets were available for the same species. $V_{\max } K_{\mathrm{m}}$ and $\alpha$ for micro- versus macroalgae were tested for significant differences by the KolmogorovSmirnoff 2-sample test (Campbell 1967).

The relationship between kinetic parameters ( $V_{\max }$ $K_{\mathrm{m}}$ and $\alpha$ ) and $\mathrm{SA}: \mathrm{V}$ were evaluated by linear regression. All data were logarithmically transformed to conform with the requirements of linear regression analysis, which were fitted using geometric mean regression (type 2 regression, sensu Sokal \& Rolff 1981). The slope of the geometric mean regression was tested (t-test) against 0 (no scaling with SA:V) applying $95 \%$ confidence limits calculated according to Hofman et al. (1986).

\section{RESULTS}

Nitrogen uptake kinetics differed substantially between micro- and macroalgae, and microalgae had 
significantly higher $\mathrm{SA}: \mathrm{V}$ ratios than macroalgae (Figs. $1 \& 2)(p<0.01)$. Although the size-range from the smallest microalgae to the largest macroalgae covered a $10^{15}$-fold change in fresh weight, the full range for $\mathrm{SA}: \mathrm{V}$ was not larger than $10^{4}$-fold because most macroalgae are flat and deviate more from the spherical form than unicellular organisms.

Maximum uptake rates of both ammonium and nitrate by microalgae were significantly higher $(p<$ 0.01) than maximum rates by macroalgae. Uptake rates at low substrate concentrations $(\alpha)$ varied in a similar manner so that the highest values occured among microalgae $(p<0.01)$. In contrast, the halfsaturation constants for uptake were significantly lower $(p<0.05)$ in microalgae compared to macroalgae. Thus, microalgae were better at harvesting nitrogen from the external environment than macroalgae.

Maximum uptake rates of ammonium and nitrate were both strongly correlated with $\mathrm{SA}: \mathrm{V}$ across the entire size range of micro- and macroalgae (Fig. 3A, B). $V_{\max }$ for nitrate increased slightly faster with increasing $\mathrm{SA}: \mathrm{V}$ (slope 0.66) than $V_{\max }$ for ammonium (slope 0.61). Variations in SA:V could account for $53 \%$ and $72 \%$ of the variation in $V_{\max }$ for ammonium and nitrate, respectively. The residual variation is, nevertheless, substantial because $V_{\max }$ could vary 10 - to 100 -fold for a given $\mathrm{SA}: \mathrm{V}$ level.

$K_{\mathrm{m}}$ for ammonium and nitrate uptake decreased with increasing SA:V (Fig. 3C, D), such that lower nutrient concentrations in the external medium are needed to half-saturate (and saturate) uptake of algae with high

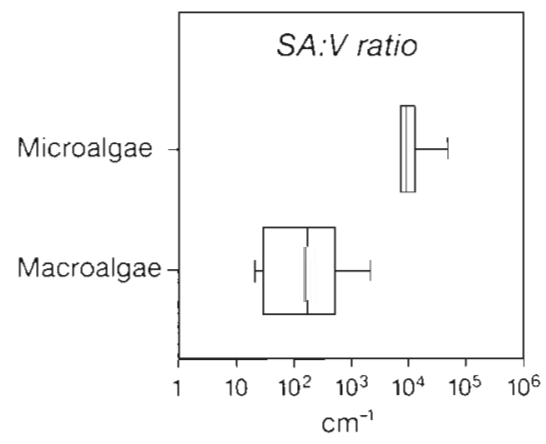

Fig. 1. Box plots showing the distribution of relative surface area (SA:V) for micro- and macroalgae respectively. Boxes encompass the 25 and $75 \%$ quartiles of all data for each algal type, the central line represents the median and bars extend to the minimum and maximum values

$\mathrm{SA}: \mathrm{V}$. The slope of the regression between $K_{\mathrm{m}}$ and $\mathrm{SA}: \mathrm{V}$ was less than 1 ( -0.68 for ammonium, -0.58 for nitrate) and the variance of $K_{\mathrm{m}}$ attributable to changes in SA:V was relatively small ( $33 \%$ for ammonium and $40 \%$ for nitrate).

The efficiency of nutrient uptake at low external concentrations $(\alpha)$ also increased with SA:V (Fig, 3E, F). The size-dependence was stronger for $\alpha$ than for $V_{\max }$ as the slopes of $\alpha$ versus SA:V were higher than 1.0 (1.01 for ammonium and 1.16 for nitrate). Variations in SA:V explained $50 \%$ and $84 \%$ of the variation in $\alpha$ for ammonium and nitrate uptake, respectively. Statistical details related to Fig. 3 are given in Table 1.
Fig. 2. Box plots showing the distribution of (A) ammonium and (B) nitrate uptake kinetics for micro- and macroalgae respectively. Boxes encompass the 25 and $75 \%$ quartiles of all data for each algal type, the central line represents the median and bars extend to the minimum and maximum values
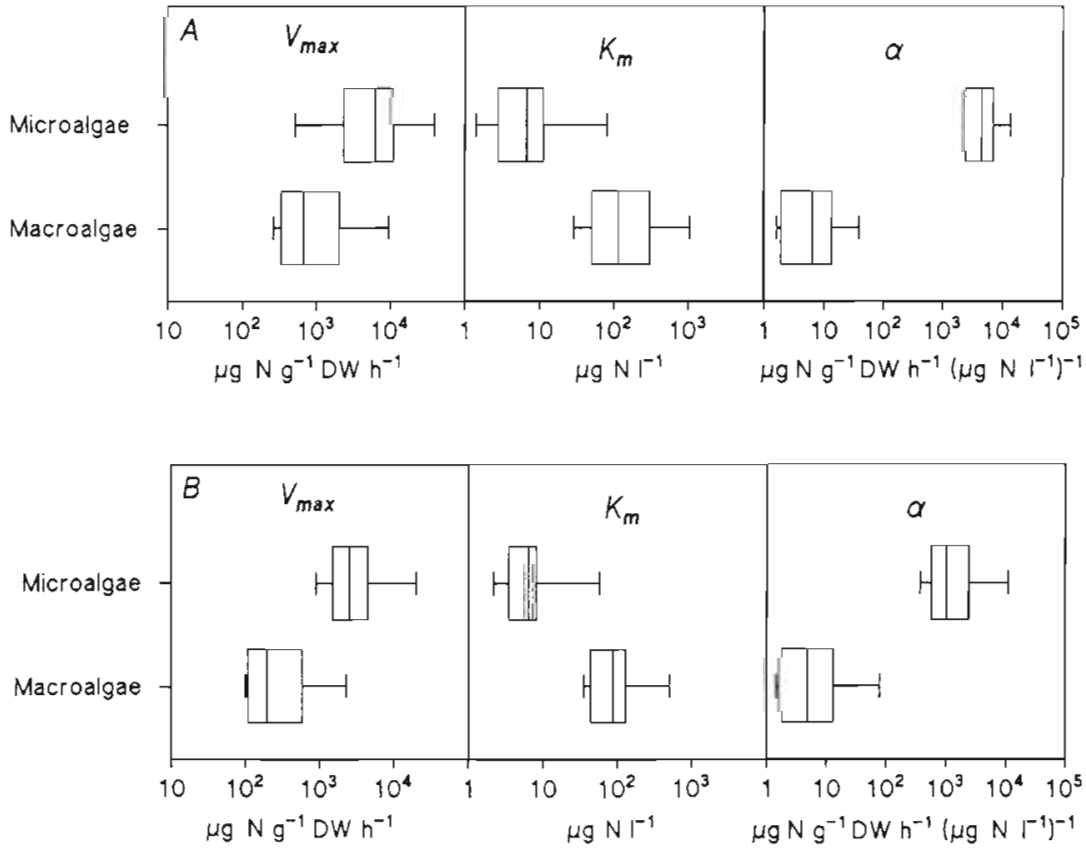


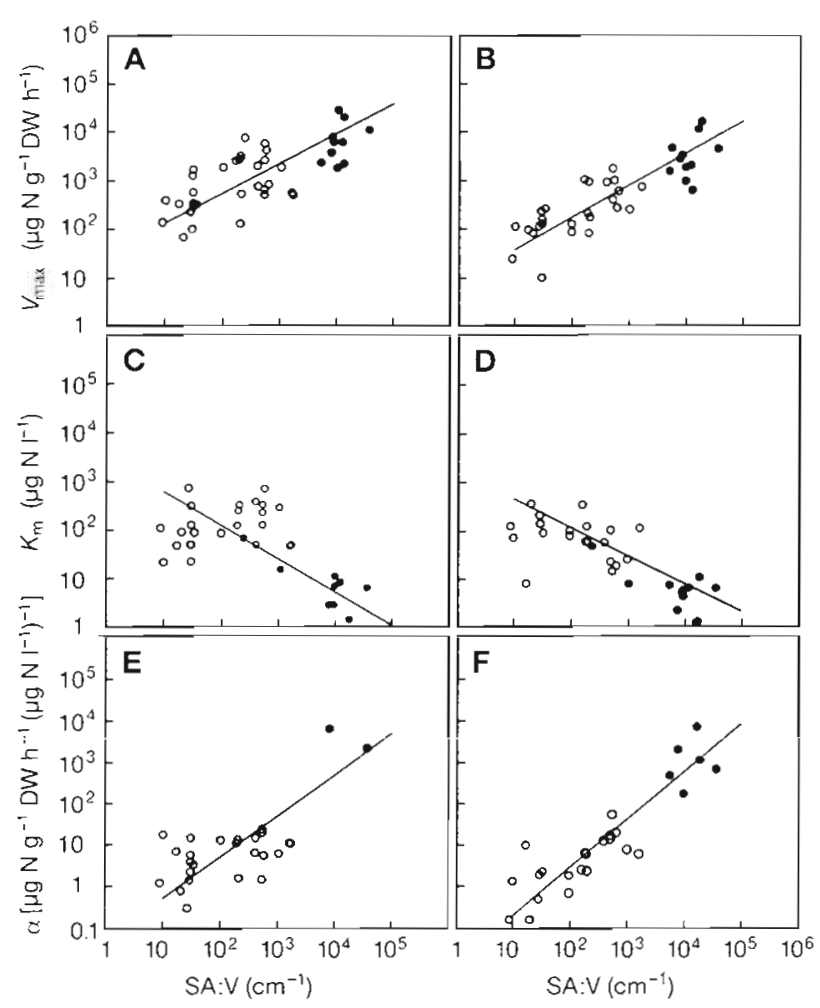

Fig. 3. Correlation of nitrogen uptake kinetics with relative surface area (SA:V) in micro-( $\bullet$ and macroalgae (O). (A) $V_{\text {max }}$ $\left(\mathrm{NH}_{4}{ }^{+}\right)$, (B) $V_{\max }\left(\mathrm{NO}_{3}{ }^{-}\right)$, (C) $K_{\mathrm{m}}\left(\mathrm{NH}_{4}{ }^{+}\right)$, (D) $K_{\mathrm{m}}\left(\mathrm{NO}_{3}{ }^{-}\right)$, (E) $\alpha$ $\left(\mathrm{NH}_{4}{ }^{+}\right),(\mathrm{F}) \propto\left(\mathrm{NO}_{3}{ }^{-}\right)$. Each data point represents the median value for a species and relationships describe the geometric mean regression analysis

\section{DISCUSSION}

\section{Size-dependence of nitrogen uptake}

The parameters describing nitrogen uptake kinetics differed substantially among algae with apparent contrasting size (micro- versus macroalgae). Microalgae were able to take up nitrogen much faster per unit of biomass than macroalgae at both high and low sub-

Table 1. Summary of the regression statistics that describe the nitrogen uptake kinetics (Fig. 3) of algae as a function of their surface area to volume ratio (SA:V) in double logarithmic plots of the form $y=a x^{b}$ Units in Fig. 3

\begin{tabular}{|lcccc|}
\hline Relationship & $a$ & $b(95 \% \mathrm{CL})$ & $\mathrm{r}^{2}$ & $\mathrm{n}$ \\
\hline$V_{\max }\left(\mathrm{NH}_{4}^{+}\right)$vS SA:V & 33.1 & $0.61(0.40,0.85)$ & 0.53 & 40 \\
$V_{\max }\left(\mathrm{NO}_{3}\right)$ vS SA:V & 8.1 & $0.66(0.49,0.85)$ & 0.72 & 36 \\
$K_{\mathrm{m}}\left(\mathrm{NH}_{4}{ }^{+}\right)$vS SA:V & 2818 & $-0.68(-0.41,-1.00)$ & 0.33 & 33 \\
$\left.K_{\mathrm{m}}\left(\mathrm{NO}_{3}\right)^{-}\right)$vs SA:V & 1791 & $-0.58(-0.31,-0.89)$ & 0.40 & 32 \\
$\alpha\left(\mathrm{NH}_{4}{ }^{+}\right)$vS SA:V & 0.05 & $1.01(0.75,1.35)$ & 0.50 & 26 \\
$\alpha\left(\mathrm{NO}_{3}^{-}\right)$vS SA:V & 0.01 & $1.16(1.00,1.37)$ & 0.84 & 26 \\
\hline
\end{tabular}

strate concentrations, and also had significantly higher affinities for nitrogen than macroalgae. These typical differences in nitrogen kinetics among small and large algae have commonly been attributed to size-specific differences in relative surface area (Malone 1980 , Wallentinus 1984, Turpin 1988, Carpenter 1990), because inorganic nutrients, like other resources, have to be transported across the surface to become available for metabolism within the algae. Our analysis has demonstrated that variations in the kinetic parameters could be attributed to changes in SA:V over a sizerange including both micro- and macroalgae. These results agree with previously described relationships between $V_{\max }$ and SA:V within narrow size-ranges (e.g. phosphorus uptake in phytoplankton, Smith \& Kallf 1982, phosphorus and nitrogen uptake in a few macroalgae, Odum et al. 1958, Rosenberg \& Ramus 1984 ) and demonstrate the existence of a general coupling between physiological and morphological properties in algae.

Changes in SA:V explained only 53\% (ammonium) and $72 \%$ (nitrate) of the variation in $V_{\max }$. Overall, the precision of the allometric relationships was, therefore, not very high probably because nitrogen uptake is a plastic property, which is difficult to measure and compare among species because of intraspecific and experimental variation. Our findings also suggest that single measurements of nitrogen uptake may be rather unreliable, and that such measurements should always be compared with other published values for the same, or closely related, species before they are presented in published reports. If $V_{\max }$ was controlled solely by the surface area available for uptake, it should increase proportionally to SA:V. However, $V_{\max }$ for both ammonium and nitrate increased with a slope significantly lessthan unity, suggesting that $V_{\max }$ is smaller per unit of surface area in small algae (assuming that volume to biomass ratios are identical among small and large organisms). Experimental conditions could have influenced the slope of $V_{\max }$ on SA:V as the time scale involved in uptake experiments of nitrogen has a significant effect on the rates measured because of surge uptake (i.e. initially enhanced uptake rate). Surge uptake persists for seconds to minutes in microalgae and is, therefore, difficult to measure (Harrison et al. 1989), while it lasts for minutes to hours in macroalgae (Haines \& Wheeler 1978, Harrison \& Druehl 1982, Pedersen 1994). Reported $V_{\max }$-values for microalgae may, therefore, represent assimilation rates rather than surge uptake rates, whereas the reverse is true for macroalgae. Hence, experimental conditions may cause a general underestimation of $V_{\max }$ in microalgae relative to those in macroalgae, leading to a lower slope in the broad regression of $V_{\max }$ on $\mathrm{SA}: \mathrm{V}$ 
Broad-scale comparisons of species based on values in the literature have to be treated with caution whatever their subject, but it is particularly important to be cautious here because nitrogen uptake processes are strongly dependent on species acclimatization and experimental conditions. Intraspecific variability in uptake parameters is extensive when examined by different researchers or under different conditions. To exploit the full potential of comparative physiological ecology in the future it is, therefore, essential that researchers examine the significant features across wide scales of plant sizes (e.g. microalgae to macroalgae) using similar methodology.

The efficiency to take up nitrogen at low ammonium and nitrate concentration $(\alpha)$ were both proportionally scaled to relative surface area (Fig. 3E, F, Table 1). The scaling of $\alpha$ on $\mathrm{SA}: \mathrm{V}$ was much stronger (slope $>1.0$ ) than was the scaling of $V_{\max }$. The rationale for the dependence of $\alpha$ on $\mathrm{SA}: \mathrm{V}$ is basically the same as for $V_{\max }$ although an even stronger dependency must be expected (Kiørboe 1993) because diffusive limitation of nutrients is the rate limiting step for uptake at low substrate concentrations. Nutrient transport across the boundary layer depends on diffusive movement along concentrations gradients which are not sufficiently steep to saturate the uptake sites at low bulk concentrations of nutrients. The thickness of the boundary layer increases with increasing distance from the leading edge, i.e. with increasing organism size. Accordingly, algae with high $\mathrm{SA}: \mathrm{V}$ are expected to possess thinner boundary layers than algae with small SA:V which consequently are more likely to suffer from diffusive limitation at low substrate concentrations. However, the experimental stirring regime is important in this context because increased flow around the organisms leads to decreased thickness of the boundary layer (Munk \& Riley 1952, Gavis 1976). It was not possible, however, to quantify the influence of the flow conditions on the data obtained from the literature.

$K_{\mathrm{m}}$ decreased as a function of increasing SA:V although the variation accounted for was relatively small for both ammonium and nitrate. $K_{\mathrm{m}}$ is a mathematical abstraction influenced by the properties of $V_{\max }$ and $\alpha$ (Healey 1980). While $V_{\max }$ and $\alpha$ were both positively scaled to $\mathrm{SA}: \mathrm{V}$, the relation of $\alpha$ to $\mathrm{SA}: \mathrm{V}$ was stronger (steeper slope) than for $V_{\text {max }}$ and hence, $K_{\mathrm{m}}$ should be inversely related to SA:V as $K_{\mathrm{m}}$ equals $V_{\max }: \alpha . K_{\mathrm{m}}$ can be used to define the external concentration that yields half the saturated uptake rate, but it is frequently used to infer that species with low $K_{\mathrm{m}}$ are more efficient in terms of nutrient uptake than species with high $K_{\mathrm{m}}$, which is simply not true (Healey 1980).

\section{Physiological and ecological consequences of size- dependent nitrogen uptake}

The observed relationships between nitrogen uptake rate and algal size (SA:V) suggest that small algae are generally better at acquiring resources (i.e. carbon, nitrogen, phosphorus and light) from the external environment than are large algae. The results presented here add to the observed relationships between phosphorus uptake rate and algal size in phytoplankton (Smith \& Kalff 1982) and macroalgae (Odum et al. 1958), whereas relationships between carbon uptake rate and algal size have yet to be established. The efficiency of photon capture per unit of biomass is also higher among small algae than large algae, thus demonstrating that the acquisition of resources is generally size-dependent as recently reviewed and synthesized by Agusti et al. (1994). High acquisition rate of resources among small algae allows high metabolic rates to occur as indeed observed for photosynthetic and respiratory rates in microalgae (Banse 1976, Littler \& Littler 1980, Markager \& SandJensen 1994). The combination of fast resource capture and high metabolic rates can, in turn, account for the potentially higher growth rates among small algae of high SA:V than in larger forms with low SA:V (Nielsen \& Sand-Jensen 1990).

The combination of large $\mathrm{SA}: \mathrm{V}$, high resource acquisition and high growth rate has often been assumed to imply that smaller algae may be competitively superior under low nitrogen availability (Eppley et al. 1969, Laws 1975, Malone 1980, Schlesinger et al. 1981). However, high biomass-specific uptake capacity is not, in itself, a sufficient feature to ensure high abundance for small algae under low nitrogen availability because the abundance depends on several ecological processes other than the resource capture alone. The balance between nutrient uptake, nutrient requirements, cell growth and loss rates due to grazing and physical processes will finally determine the abundance and success of a given alga in the environment. The requirement for nitrogen to sustain maximum growth rate is a function of the species-specific maximum growth rate and the nitrogen demand of the tissue, both of which increase with decreasing algal size. The average specific growth rate of microalgae is at least 8-fold higher than that of macroalgae (Nielsen \& Sand-Jensen 1990) and tissue nitrogen is considerably higher in microalgae (1.0 to $14.0 \% \mathrm{~N}$ of dry wt) than in macroalgae $(0.4$ to $4.4 \% \mathrm{~N}$ of dry wt; Duarte 1992), leading to substantially higher nitrogen requirements in microalgae. Thus, it is possible that nitrogen uptake capacity and nitrogen requirements may be 'perfectly' scaled to each other regardless of algal size and, therefore, no specific size-class of algae should be 
significantly better suited to sustain high growth rates (relative to the intrinsic maximum capacity) under low nitrogen availability than any other. Small algae, with their high rates of nutrient uptake and growth should, in contrast, be favored when the nitrogen availability is high, because the high loss rates due to grazing, sedimentation, etc., that typically occur among small algae, can be balanced, or even exceeded, under such circumstances. Low nitrogen availability may provide room for larger algae to become dominant despite inherently slower growth rates and possible nitrogen limitation because loss rates are slower.

In conclusion, small algae achieve faster nitrogen uptake rates at both low and high substrate concentrations than large algae. These size-dependent differences in uptake kinetics can largely be explained by size-specific changes in relative surface area as all kinetic parameters are closely related to $\mathrm{SA}: \mathrm{V}$. The relationships of nitrogen uptake parameters to $\mathrm{SA}: \mathrm{V}$ are, however, relatively imprecise and the substantial remaining variation can be assigned to species-specific variations in uptake potential, experimental errors and differences in experimental conditions. Because of this finding, we enter a plea that, in the future, authors of original studies of nitrogen uptake in selected algae should make more effort to relate their results to those of other workers. The overall scaling of nitrogen uptake to algal size corresponds to the size-scaling of other functional properties, such as capture of other nutrients, light absorption, photosynthetic rate and growth rate, showing the existence of general scaling of functional properties to morphological properties. High capability of resource capture among small algae does not, however, automatically lead to competitive superiority in small algae under low nitrogen availability as several other aspects control species distribution and abundance in nature.

Acknowledgements. This study was supported by a 'HAV-90' grant from the Danish National Agency of Environmental Protection. We greatly appreciate the constructive comments received from Carlos M. Duarte, Matt Dring and 2 anonymous reviewers

\section{LITERATURE CITED}

Agusti, S. (1991). Allometric scaling of light absorption and scattering by phytoplankton cells. Can. J. Fish. Aquat. Sci. 48: 763-767

Agusti, S., Enriquez, S., Frost-Christensen, H., Sand-Jensen, K., Duarte, C, M. (1994). Light harvesting among photosynthetic organisms. Funct. Ecol 8: 273-279

Banse, K. (1976). Rates of growth, respiration and photosynthesis of unicellular algae as related to cell size - a review. J. Phycol. 12: 135-140

Campbell, R. C. (1967). Statistics for biologists. Cambridge University Press, Cambridge
Carpenter, R. C. (1990). Competition among marine macroalgae: a physiological perspective. J. Phycol. 26: 6-12

Conway, H. L., Harrison, P. J., Davis, C. O. (1976). Marine diatoms grown in chemostats under silicate or ammonium limitation. II. Transient response of Skeletonema costatum to single addition of the limiting nutrient. Mar. Biol. 35 $187-199$

Duarte, C. M. (1992). Nutrient concentration of aquatic plants patterns across species. Limnol. Oceanogr. 37: 882-889

Eppley, R. W., Rogers, J. N., McCarthy, J. J. (1969). Halfsaturation constants for uptake of nitrate and ammonium by marine phytoplankton. Limnol. Oceanogr. 19: 912-920

Fong, P., Zedler, J. B., Donohoe, R. M. (1993). Nitrogen vs phosphorus limitation of algal biomass in shallow coastal. lagoons. Limnol. Oceanogr. 38: 906-923

Fujita, R. M. (1985). The role of nitrogen status in regulating transient ammonium uptake and nitrogen storage by macroalgae. J. exp. mar. Biol. Ecol. 92: 283-301

Fujita, R. M., Wheeler, P. A., Edwards, R. L. (1988). Metabolic regulation of ammonium uptake by Ulva rigida (Chlorophyta): a compartmental analysis of the rate limiting step for uptake. J. Phycol. 24: 560-566.

Gavis, J. (1976). Munk and Riley revisisted: nutrient diffusion transport and rates of phytoplankton growth. J. mar. Res. 34: $161-179$

Goldman, J. C., Glibert, P. M. (1982). Comparative rapid ammonium uptake by four species of marine phytoplankton. Limnol. Oceanogr. 27: 814-827

Haines, K. C., Wheeler, P. A. (1978). Ammonium and nitrate uptake by the marine macrophyte Hypnea musciformis (Rhodophyta) and Macrocystis pyrifera (Phaeophyta). J. Phycol. 14: 319-324

Hanisak, M. D., Littler, M. M., Littler, D. S. (1988). Significance of macroalgal polymorphism: intraspecific test of the functional-form model. Mar. Biol. 99: 157-165

Harris, G. P. (1986). Phytoplankton ecology. Cambridge University Press, Cambridge

Harrison, P. J., Druehl, L. D. (1982). Nutrient uptake and growth in the Laminariales and other macrophytes: a consideration of methods. In: Srivastava, L. M. (ed.) Synthetic and degradative processes in marine macrophytes. Walter de Gruyter, Berlin

Harrison, P. J., Parslow, J. S., Conway, H. L. (1989). Determination of nutrient kinetic parameters: a comparison of methods. Mar. Ecol. Prog. Ser. 52: 301-312

Healey, F. P. (1980). Slope of the Monod equation as an indicator of advantage in nutrient competition. Microb. Ecol. 5: $281-286$

Hecky, R. E., Kilham, P. (1988). Nutrient limitation of phytoplankton in freshwater and marine environments: a review of recent evidence on the effects of enrichment. Limnol. Oceanogr. 33: 796-822

Hofman, M. A., Laan, A. C., Uylings, H. B. M. (1986). Bivariate linear models in neurobiology: problems of concept and methodology. J. Neurosci. Meth. 18: 103-114

Kiorboe, T (1993). Turbulence, phytoplankton cell size, and the structure of pelagic food webs. Adv. mar. Biol. 29: $1-72$

Lapointe, B. E. (1987). Phosphorus- and nitrogen-limited photosynthesis and growth of Gracilaria tikvahiae (Rhodo. phyceae) in the Florida Keys: an experimental field study. Mar. Biol. 93: 561-568

Laws, E. A. (1975). The importance of respiration losses in controlling the size distribution of marine phytoplankton. Ecology 56: 419-426

Littler, M. M., Littler, D. S. (1980). The evolution of thallus form and survival strategies in benthic marine macro- 
algae: field and laboratory test of a functional form model. Am. Nat. 116: 25-44

Malone, T. C. (1980). Algal size. In: Morris, I. (ed ) The physiological ecology of phytoplankton. Blackwell Scientific Publications, Oxford

Markager, S., Sand-Jensen, K. (1994). The physiology and ecology of light-growth relationships in macroalgae. In: Round, F. E., Chapman, D. J (eds.) Progress in phycological research, 10. Biopress Ltd, Bristol, p. 210-298

Munk, W. H., Riley, G. A. (1952). Absorption of nutrients by aquatic plants. J. mar. Res. 11:215-240

Nielsen, S. L., Sand-Jensen, K. (1990). Allometric scaling of maximal photosynthetic growth rate to surface/volume ratio. Limnol. Oceanogr. 35: 177-181

Odum, E. P., Kuenzler, E. J., Blunt, M. X. (1958). Uptake of ${ }^{32} \mathrm{P}$ and primary productivity in marine benthic algae. Limnol. Oceanogr. 3: 340-345

Pedersen, M. F. (1994). Transient ammonium uptake in the macroalga Ulva lactuca (Chlorophyta): nature, regulation, and the consequences for choice of measuring technique. J. Phycol. 30: 980-986

Raven, J. A. (1984). Energetics and transport in aquatic plants. A. R. Liss, New York

Reynolds, C. (1984). The ecology of freshwater phytoplankton. Cambridge University Press, Cambridge

Rosenberg, G., Ramus, J. (1984). Uptake of inorganic nitrogen and seaweed surface area:volume ratios. Aquat. Bot. 19: $65-72$

This article was submitted to the editor
Runge, J. A., Ohman, M. D. (1982). Size fractionation of phytoplankton as an estimate of food available to herbivores. Limnol. Oceanogr. 27: 570-576

Schlesinger, D. A., Molot, L. A., Shuter, B. J. (1981). Specific growth rates of freshwater phytoplankton in relation to cell size and light intensity. Can. J. Fish. Aquat. Sci. 28: $1052-1058$

Shuter, B. J. (1978). Size dependence of phosphorus and nitrogen subsistence quotas in unicellular microorganisms. Limnol. Oceanogr. 23: 1248-1255

Smith, R. E. H., Kalff, J. (1982). Size dependent phosphorus uptake kinetics and cell quota in phytoplankton. J. Phycol. 18: $275-284$

Sokal, R. R., Rohlf, F. J. (1981). Biometrics, 2nd edn. W. H Freeman and Company, San Francisco

Turpin, D. H. (1988). Physiological mechanisms in phytoplankton resource competition. In: Sandgren, C. D. (ed.) Growth and reproductive strategies of freshwater phytoplankton. Cambridge University Press, Cambridge

Wallentinus, I. (1984). Comparison of nutrient uptake rates for Baltic macroalgae with different thallus morphologies Mar. Biol. 80: 215-225

Watson, S., McCauley, E. (1988). Contrasting patterns of netand nanoplankton production and biomass among lakes. Can. J. Fish. Aquat. Sci. 45: 915-920

Wheeler, P. A. (1983). Phytoplankton nitrogen metabolism. In: Carpenter, E. J., Capone, D. G. (eds.) Nitrogen in the marine environment. Academic Press, New York

Manuscript first received: April 14, 1994

Revised version accepted: December 5, 1994 